\title{
O primeiro grande movimento social brasileiro: a campanha abolicionista $(1868-1888)^{1}$
}

\author{
The first great Brazilian social movement: \\ the abolitionist campaign (1868-1888)
}

\begin{abstract}
Ênio José da Costa Brito*
"A comemoração da abolição pela elite imperial minimizou a importância do movimento abolicionista e reiterou o mito fundacional do Império, uma comunidade imaginada que expurgou o africano"

"Mesmo na celebração de sua liberdade, o ex-escravo foi escamoteado".
\end{abstract}

(ALONSO, 2015, p.369)

\section{Resumo}

\begin{abstract}
Nos últimos anos, o processo de Abolição tem ocupado a agenda dos historiadores(as), um dos estudos mais amplos é o Angela Alonso, intitulado Flores, votos e balas. O movimento abolicionista Brasileiro (1868-1888). Para a autora, a contribuição do movimento abolicionista para o termino da escravidão, ainda não foi devidamente valorizado pela historiografia. Processo dividido por ela em três fases, cada uma com sua especificidade: na das flores(1868-1878), o movimento abre-se para o espaço público, na dos votos (1879-1885) atua nos espaços políticos e na das balas (1885-1888), mergulha na clandestinidade. Ao apresentar as três fases, tem sempre presente as relações entre a campanha abolicionista e o sistema político. O reflexo na análise desta acentuada perspectiva política foi ter deixando na sombra a efetividade escrava ao longo de todo o processo. Flores, votos e balas recoloca na agenda historiografia brasileira o debate sobre as causas que levaram a abolição e, implicitamente convida os leitores(as) a refletirem sobre nossos problemas atuais, que tem suas raízes na mentalidade escravocrata que permanece silenciosa mas viva na alma brasileira.
\end{abstract}

Palavras-chave: Movimento social, campanha abolicionista, escravidão, aboliçao; Lei Áurea

\footnotetext{
Artigo submetido em 08 de janeiro de 2017 e aprovado em 25 de agosto de 2017.

${ }^{1}$ O objetivo desta Comunicação-resenha é oferecer ao leitor o núcleo temático do livro "Flores, votos e balas. O Movimento Abolicionista brasileiro (1868-1888)", de Angela Alonso. Nas observações finais vamos explicitar a crítica fundamental da obra de Alonso. O que justifica a opção de não se elaborar uma "resenha clássica" é o fato de termos em mãos uma obra, ainda pouco conhecida do público em geral, que inova na forma de apresentar o movimento abolicionista, obra complexa e ampla. Ao longo da resenha selecionamos passagens marcantes do texto, mesmo estendendo um pouco, para que o leitor possa ter a voz da autora.

* Doutor em Teologia (PUG-Roma), professor titular do Programa de Estudos Pós-Graduados em Ciência da Religião da Pontifícia Universidade Católica de São Paulo. Coordenador do Grupo de Pesquisa Veredas: O imaginário religioso Brasileiro, reconhecido pelo CNPq. Vice Coordenador do CECAFRO e editor da Revista Último Andar. País de Origem: Brasil. E-mail: brbrito@uol.com.br
} 


\section{Introdução}

A razão de fundo do livro "Flores, votos e balas. O Movimento Abolicionista brasileiro (1868-1888)", de Angela Alonso, é o fato do não reconhecimento pleno da importância do movimento abolicionista para o término da escravidão brasileira. No livro, a autora "reconstrói a trajetória da grande, estruturada e duradora rede de ativistas, associações e manifestações públicas antiescravistas que, a exemplo de outros países, conformou um movimento social nacional - o primeiro no Brasil de seu gênero” (ALONSO, 2015, p.17)².

O texto nos seus nove capítulos acompanha as retóricas, estratégias e arenas dos movimentos abolicionistas, que a conjuntura política possibilita e as inúmeras tensões com os governos e os escravistas, “operando sucessivamente como flores (no espaço público), votos (na esfera político- institucional) e balas (na clandestinidade), num jogo de ação e reação de duas décadas (1868-1888) (p.19)”.

Nesta Resenha de Conteúdo, nossa preocupação num primeiro momento é percorrer o texto, recolhendo as ideias básicas, cuidando em preservar em parte a estratégia narrativa do mesmo e em seguida tecer breves comentários. Temos consciência de que a aproximação da obra não colhe toda a sua riqueza, apenas consegue constelar alguns fatos e argumentos. Fica o convite para que o leitor preencha as lacunas no contato com a obra.

\section{Narrando trajetórias abolicionistas frente ao "escravismo de circunstância" e a Lei do Ventre Livre}

A inflexão na vida de André Rebouças (1838-1898) - misto de engenheiro, empreendedor e político - ocorreu ao receber, em 1867, o pedido para alforriar um operário que trabalhava numa das empresas que geria.

\footnotetext{
${ }^{2}$ Passaremos a indicar apenas as páginas da obra.
} 
Em 1868, colocou-se a serviço do abolicionismo, momento de grande perturbação, que começou em 1826, com a pressão inglesa pelo fim do tráfico, só abolido em 1850. A conjuntura política do século XIX, após o ciclo das abolições, criara um novo ambiente político internacional desfavorável à escravidão. Essa dinâmica anti-escravista não ecoou no Brasil, pois a escravidão "era a pedra angular da economia, de partidos e da sociedade aristocrática desde as origens da nação" (p.28). O Império, graças a oposição sistemática do partido conservador a qualquer mudança na questão servil, continuava escravocrata, enquanto a escravidão acabava pelo mundo.

O médico e educador Abílio César Borges (1826-1891), barão de Macaúbas, da primeira geração de ativistas desenvolveu uma série de atividades antiescravistas: aliança com abolicionistas estrangeiros, associativismos, manifestações, panfletos, jornais, (O Abolicionismo), utilizando o espaço público extra parlamento, como salões de agremiações, escolas, câmaras municipais. Para ele, “o ativismo de elite precisava desabrochar em mobilização social” (p.43).

Rebouças, por sua vez, na sua militância abolicionista "transferiu para a política seu modus operandi de empresário, o lobby” (p.44), visando ir além das estratégias empregadas por Borges. Passou, então a transitar nos meandros institucionais para construir pontes entre o associativismo abolicionista e o governo, para articular a elite social, sociedade de corte e sistema político.

José Maria Paranhos, o visconde do Rio Branco, assumiu o governo em 7 de março de 1871, em 12 de março enviou o projeto sobre a liberdade do ventre com dez artigos, para a discussão na Câmara e depois no Senado. "O primeiro e principal previa, como a Lei Moret espanhola, liberdade do ventre com aprendizagem, isto é, o filho da escrava nascido a partir de 1871, ficaria até os oito anos sob a guarda do proprietário, que, então optaria por entregá-lo ao Estado, mediante indenização, ou usufruir do seu trabalho compulsório até os 21 anos” 
(p.56)3. O Projeto acolhia, também, três formas de libertação: pelo pecúlio, pelo direito de redenção e pelo Fundo de Emancipação.

O repertório moral - conjunto limitado de esquemas de pensamento -, escravista do Ocidente foi utilizado pelos opositores do projeto de lei, em especial, por Paulino Soares de Sousa e José de Alencar.

Quando a questão do ventre livre se fez presente no cenário escravista brasileiro? Em 1860, como uma retórica de reação a ameaça das sociedades abolicionistas. A discussão do ventre livre (1871) deixou claro que os escravistas brasileiros não eram de princípio, mas de circunstância. "Difuso, sinuoso, fragmentário, o escravismo de circunstância transpirou em discursos parlamentares de oposição ao projeto do ventre livre" (p.61). Nele defendia-se não a escravidão, mas a situação escravista com os seguintes argumentos da retórica de reação: "o efeito perverso da reforma, sua futilidade e a ameaça que representava para a ordem social" (p.61).

O partido conservador, tendo à frente Paulino Soares de Sousa fez uma oposição duríssima a Rio Branco, acusando-o de irresponsável, arbitrário, moço de recado e a medida do ventre livre como "antijurídica, injusta, perturbadora, imprevidente, desumana e opressora" (p.64). A oposição ao ventre livre não ficou coarctada aos discursos mas promoveu um ativismo, o escravismo político, conjunto de práticas de resistência como petições, discursos, Clubes da Lavoura.

Debates intermináveis e exaltados se seguiram até a aprovação da lei "A Lei do Ventre Livre passou com atenuações e efetividade futura, mas colocava em xeque a escravidão e o que nela assentava" (p.81-82).

\footnotetext{
33 Ver MACHADO, 2015. No primeiro artigo Flávio Gomes e Maria Helena P.T. Machado propõem "uma avaliação dos caminhos temáticos e percursos historiográficos a respeito do tema destacando as possibilidades de se elaborar conexões analíticas entre expectativas e percepções de liberdade e autonomia, envolvendo escravos, roceiros, quilombolas e forros antes e depois da abolição" (Cf., p.20).
} 
O ritmo lento do processo de modernização conservadora acelera-se na década de 1870, viabilizando a difícil internalização pela população do repertório moral abolicionista. A contestação moral veio do espiritismo e do Romantismo, que entre nós legitimou e combateu a escravidão. Entre nós não ocorreu o questionamento cristão da escravidão, “a sensibilização antiescravista coube sobretudo as artes" (p.98).

A tópica do progresso, da compaixão e do direito natural à liberdade deram o lastro ao abolicionismo brasileiro, que "usou a tópica do direito em três chaves: a filosófica, do direito natural; a jurídica, de tribunal e a política, de associação com a construção da cidadania” (p.101). Na prática, os três esquemas se misturavam numa retórica de mudança, que ofereceu as bases discursivas para o ativismo em favor dos escravos e para enfrentar a retórica da reação. Retórica usada a seu modo por cada abolicionista, assim "o esquema interpretativo do direito casou-se logo e bem com a estratégia de Luís Gama” (p.103), que explorava as ambiguidades e lacunas da legislação, mormente das leis de 1831 e 1871, numa estratégia de judicialização da luta abolicionista4.

Rebouças, ao contrário de Luís Gama, estava integrado na elite social e nas entranhas políticas do Segundo Reinado. Era um abolicionista cerebral, faltava-lhe a alma abolicionista. Considerava-se membro efetivo da aristocracia social. Ao contrário de Luís Gama, Rebouças alcançou alta posição social que eclipsou sua cor. Isso mudou, em 1873, quando voltando da Europa aportou nos Estados Unidos - seu modelo de progresso -, onde foi humilhado, rejeitado em hotéis e restaurantes por causa de sua cor. Experiência que fez com que escolhesse como modelo o mulato Frederick Douglass, o maior dos abolicionistas negro dos Estados Unidos.

${ }^{4}$ Para uma visão ampla do ativismo de Luis Gama, ver Elciene Azevedo (1999 e 2010). 
José do Patrocínio nasceu em 1854, filho de uma liberta quitandeira e do vigário da paróquia de Campos. "Patrocínio tributou sua transmutação de algoz em paladino dos escravos à tópica romântica da compaixão” (p.114).

No pós Ventre Livre, os gabinetes conservadores conseguiram arrefecer o movimento abolicionista, com a volta dos liberais tradicionalistas ao poder em 1878, a abolição se fez presente, novamente, na agenda política, graças à incapacidade dos liberais de efetivarem a Lei do Ventre Livre. Nesse período, duas estrelas do abolicionismo emergiram, Joaquim Nabuco no Parlamento e José do Patrocínio no espaço público. "Amizade duradoura e é difícil imaginar o abolicionismo sem ela" (p.122).

Frente a uma nação que não sabia ler e sem o apoio da religião católica, Patrocínio e Rebouças "casaram intenção política com inserção cultural” (p.128), transformando as conferências em concertos, conferências -concerto. A eles se aliou Vicente Ferreira de Sousa, negro, fundador da Federação Operária e do Partido Socialista Coletivista.

As Conferências Emancipadoras eram realizadas em teatros, centros da vida social. A retórica do progresso e da compaixão eram recorrentes nas sessões, marcadas por muito entusiasmo e apreensão, por temor da represália da polícia, "a iniciativa de três negros contra uma instituição basilar do Império” (p.138).

Carlos Gomes "pertenceu à vasta trupe que fez abolicionismo com acordes e trinados, versos e folhetins" (p.139). Procurava-se sensibilizar a população com poesias, romances, pelas e caricaturas.

O movimento ao alargar as suas bases, incluiu as mulheres e os escravos, entre as primeiras destacaram Chiquinha Gonzaga, Luísa Regadas e Josefa Mercedes de Oliveira. Para João Clapp, criador do Clube dos Libertos de Niterói, o movimento contaminou todos os estratos sociais, abrangendo no dizer de Patrocínio, “cidadãos de todas as classes" (p.148). 
Com as conferências-concerto a política no Brasil, passou do Parlamento ao espaço público: "Se Rebouças, o cerebrino, foi o organizador, Patrocínio, impulsivo e um tanto inconsequente, seria o agitador, sem o qual nenhum movimento social prospera" (p.151).

\section{Tecendo alianças internacionais e nacionais para consolidar o movimento abolicionista}

Circunstâncias sociais explicam a ascensão política de Joaquim Nabuco, nascido em 1849, membro da aristocracia social e da elite política. Em 1879, entrou para o Parlamento, com uma agenda Liberal Radical - abolição gradual e pequena propriedade -, repondo o problema na cena internacional. "A opinião do mundo inteiro está formada a este respeito. O trabalho servil tem de acabar" (p.157). Seu modelo político era William Wiberforce, ícone do abolicionismo inglês, zeloso da tradição5.

Nabuco fundou a Sociedade Brasileira contra Escravidão (SBCE), parecida com a Libertadora 7 de Setembro, de Abílio Borges. No seu ativismo político tornou-se o braço avançado no Parlamento do movimento abolicionista, levando temas das conferências-concerto e da imprensa abolicionista para dentro da casa. Gradualmente, preparou uma coalização entre os movimentos abolicionistas brasileiros e destes com os internacionais, consolidando, assim sua liderança.

O Abolicionista e a Gazeta da Tarde publicaram o manifesto da Sociedade Cearense Liberadora (SCL), que contava entre seus membros João Cordeiro, José Correia do Amaral e Frederico Borges. A sociedade agia tanto dentro da ordem como fora dela. Foi promotora da primeira greve de estivadores do Porto de Fortaleza.

${ }^{5}$ Para conhecer propostas pós-abolição na Grã-Bretanha consultar SCHAMA, 2001. 
Entre 1878 e 1885, o associativismo explodiu, graças a abertura dada pelos governos liberais. "O abolicionismo extrapolava seu perímetro político e geográfico, nacionalizava-se" (p.182).

O refluxo do movimento abolicionista se deu com a nomeação pelo Imperador de Martinho Campos para presidir o governo, em 1882, um liberal conservador, "escravocrata da gema". A queda de Martinho coincidiu com a morte em São Paulo de Luís Gama (24/8/1882). Antônio Bento assumiu o comando do abolicionismo paulista.

Ao assumir a chefia do Governo, em 3 de julho de 1882, o liberal próreforma João Lustosa da Cunha, marques de Paranaguá, trouxe de volta a abolição para a agenda do Politica. Seu substituto Lafaiete Rodrigues permaneceu pouco tempo no governo.

No entanto, o crescimento abolicionista ocorria fora do sistema político partidário, agindo em escala nacional, com estratégias renovadas, como a "campanha de libertação de territórios", iniciada no Rio de Janeiro, que em seguida, se estendeu pelas Províncias. No Ceará, foi levada adiante pela Comissão Central Emancipadora (CCE).

A Confederação Abolicionista (CA) nasceu, em 9 de maio de 1883, visando reunir os abolicionistas, tendo como sede e jornal a Gazeta da Tarde. O Manifesto da CA e $O$ Abolicionismo de Nabuco dirigiam-se as instituições políticas. "O livro fundamentava a causa, dava as razões do movimento, O Manifesto indicava uma política, a linha de ação” (p.206).

Sátiro de Oliveira Dias, ao substituir Manoel de Souza Dantas no governo do Ceará, tinha já a intenção de proclamar a abolição na Província, o que de fato ocorreu em 25 de março de 1884. Teodoro Carlos Farias Souto, ao assumir o governo amazonense, em 11 de março de 1884, seguiu o modelo de Sátiro Dias: “colaboração entre executivo provincial e movimento local” (p.213). Em maio de 1884, os últimos escravizados de Manaus foram libertados. No Rio Grande do Sul, 
"o estilo de ativismo foi o mesmo da CA: conferências-concerto, participação feminina e campanha de libertação de territórios” (p.214-215).

As mobilizações progrediam onde encontravam um Poder Executivo facilitador, como no Ceará e Manaus. As províncias da Bahia, São Paulo, Rio de Janeiro possuíam uma certa tradição abolicionista, mas avançaram lentamente devido à forte reação politicamente organizada do escravismo local. Para Rebouças, “desde o Amazonas até o Rio Grande do Sul, a máquina abolicionista está montada" (p.220).

Enquanto promovia a campanha de libertação de territórios - ou a anarquia, na opinião de escravistas da Câmara - a CA pressionava o governo com uma intensificação do uso do estilo Gama de ativismo judicial -, ações de liberdade, apelos, processos, denúncias aos tribunais e à polícia.

Em 1883, com o movimento implantado na maioria das províncias, era tempo de se pensar nas eleições de 1884 . O crescimento do movimento trouxe no seu bojo as divisões no momento de se definir os candidatos. "A Assembleia da CA, em novembro de 1883 , aplacou a cizânia interna e definiu a estratégia eleitoral" (p.225). Saíram candidatos pelo Município Neutro Patrocínio e Ferreira Araújo representando as ruas, Nabuco e Serra pelo lado do sistema político.

Nos últimos meses de 1883, a CA trabalhara na busca do reconhecimento da abolição da escravidão no Ceará, por parte do governo. Promoveu uma grande festa no Rio de Janeiro e no Ceará, enquanto Nabuco, e Patrocínio angariavam apoio no exterior. Vale lembrar que as técnicas de protesto abolicionista de 1878 a 1885 visavam angariar adeptos, tinha como símbolo as flores. "Adaptando modelos estrangeiros às contingências nacionais ou inventando formas novas, o movimento foi se apropriando do território urbano, indo dos teatros para o espaço público por excelência, a rua" (p.231). Gradualmente passou-se do associativismo de elite (1860) para um abolicionismo das ruas (1880). 


\section{Do abolicionismo de Dantas ao escravismo de Cotegipe}

"O ano de 1884 desenterrou a ira do escravismo de circunstância dos tempos do debate do ventre livre" (p.237). Manoel de Sousa Dantas, em 6 de junho de 1884, substituiu o governo de Lafaiete, que se mostrara incapaz de encarar a questão servil.

A plataforma do governo Dantas ia além da libertação dos sexagenários, uma vez que visava preparar uma nova sociedade pós -abolição. Não contando com a maioria na Câmara, ele buscou apoio fora, aliando-se com o movimento abolicionista. "Movimento e governo se amalgamavam" (p.246).

A reação escravista não tardou, sem o apoio no Parlamento migrou para as ruas, empregando os mesmos métodos dos abolicionistas. O ponto alto dessa estratégia, a proliferação de Associações e Clubes de Lavoura e a organização de uma política escravista ${ }^{6}$, que buscou também apoio no exterior e apelou para a violência e a intolerância.

A maioria da Câmara, Senado, Conselho de Estado e suas bases sociais se posicionou contra o Projeto 48. Dantas não caiu, graças ao apoio de Dom Pedro. Com a dissolução da Câmara, em 30 de julho de 1884, eleições foram convocadas para dezembro, com posse em $1^{\circ}$ de março de 1885 . A campanha eleitoral que se seguiu, deixou mais clara a aliança entre o governo e o movimento.

Na eleição do Senado, Paulinho Soares de Souza venceu dando um troco ao reformismo de Dantas e ao abolicionismo das ruas, que em 1884 obtivera resultados expressivos: 73 cidades libertadas, sendo três capitais provinciais, Fortaleza, Manaus e Porto alegre. Gradualmente, a coligação entre o movimento e o governo montou seu xadrez eleitoral, com 51 candidatos autodeclarados abolicionistas à Assembleia Geral, por catorze províncias.

\footnotetext{
${ }^{6}$ Para uma discussão sobre a política escravista, ver PARRON (2011). O autor se propõe a examinar as relações entre a instituição da escravidão e a política imperial brasileira.
} 
O país, em dezembro de 1884, presenciou uma eleição tumultuada tanto na votação quanto na apuração. Fraudes, violência, impedimentos de eleitores e impugnação da eleição em Recife. "Abolicionistas e escravistas cada qual com suas atas cantava vitória" (p.275). O reconhecimento de mandatos passava pela mesa nas mãos dos escravistas, que validou seus candidatos e invalidou os abolicionistas com pendência.

Com a queda do governo Dantas, o movimento abolicionistas derrotado na arena política voltou as ruas, tendo, apenas Nabuco como representante na Assembleia Geral.

João Mauricio Vanderlei, o barão de Cotegipe, quando assumiu em 1885 a chefia do Gabinete, "a campanha abolicionista já fizera seu maior feito, o de tornar a escravidão socialmente ilegítima” (p.280).

Após a queda de Dantas, o liberal Antônio Saraiva assumiu o governo, desfigurou o Projeto Dantas e o aprovou, em 13 de agosto de 1885, e se demitiu.

A Lei Saraiva-Cotegipe, aprovada no Senado e promulgada em 28 de setembro de 1885, foi batizada como "Lei dos Sexagenários"7. Cotegipe, para manter o statu quo, recorreu a "manipulação eleitoral, o ludíbrio da lei e a repressão aos opositores" (p.288) e implantou um Regulamento Negro. Usou e abusou do aparelho repressivo do Estado para ameaçar, perseguir e prender abolicionistas pais afora, com aval ou omissão da Coroa. Perseguidos, os abolicionistas perderam o espaço público mas ganharam a opinião pública.

Cotegipe controlava a Câmara, não o Senado, onde os abolicionistas, apoiados pelos liberais lutavam para proibir os açoites. Em 1886, a pressão internacional cresceu, pois o Brasil tornara-se o único pais escravista das Américas.

\footnotetext{
7 Ver MENDONÇA, 1999. A autora apresenta uma releitura criativa da lei ao "relacionar as posições dos deputados neste longo e
} conturbado debate às experiências da escravidão, às relações e conflitos entre senhores, escravos e libertos" (cf.p.15). 
A política de Cotegipe levou os abolicionistas a diversificarem as suas arenas de luta, a se unirem com os escravos e pôr fim a opção pela desobediência civil. "Os escravos percebendo a existência de uma rede de sustentação, ganharam incentivo para fugir. Essa convergência gerou a estratégia das rotas coletivas orientadas" (p.305). Rotas de fuga para dentro foram criadas, como Santos-Ceará-Amazonas ou Ceará-Rio de Janeiro-Rio Grande do Sul - Montevidéu. Uma densa rede de solidariedade ao Norte e ao Sul dava suporte aos acoitamentos e fugas, que cresciam com o passar do tempo.

Ao longo de 1887, Cotegipe entrou em choque com o exército várias vezes e o regime encontrava-se como um todo em crise profunda, frente a incapacidade do governo de controlar o caos social. Cotegipe ampliou consideravelmente a repressão, suscitando uma resposta violenta dos abolicionistas.

\section{A segunda Lei Áurea}

Em 1887, o escravismo perdeu o apoio do Exército e da Igreja, "da fé e da força”. O vazamento na imprensa do Manifesto Deodoro e da notícia que o Papa Leão XIII condenava a escravidão repercutiu na sociedade brasileira. Entre maio e dezembro de 1887, a Igreja aderiu a "santa causa" abolicionista.

A abolição a curto prazo, com prestação de serviços ganhava a cada dia novas adesões de senhores escravistas. Fatores políticos definiram o fim da escravidão, que continuava sendo defendida, no Senado, por Paulino, na Câmara por Andrade Siqueira e no Gabinete, por Cotegipe. Antônio Prado e João Alfredo Correia de Oliveira haviam desertado.

Cotegipe caiu em 7 de maio, a regente escolheu João Alfredo Correia de Oliveira, conservador, que no dia 12 de março, com apoio da princesa apresentou a proposta de lei para extinção imediata e incondicional da escravidão no Brasil. "Em 8 de maio, o governo encaminhou um texto de duas linhas, o mais lacônico de 
todos os projetos brasileiros sobre a escravidão "(p.347). Aprovado na Câmara e no Senado, foi promulgado no Largo do Paço, no dia 13 de maio às três da tarde:

Artigo $1^{\circ}$ É declarada extinta desde a data desta lei a escravidão no Brasil

Artigo $2^{\circ}$ Revogam-se disposições em contrário.

Passada a festa, os escravistas deram início a um novo movimento o indenizismo; os abolicionistas se dividiram quanto ao destino do ex-cativo direitos sociais ou democracia rural -, e quanto ao modelo político Monarquia (Rebouças, Nabuco, Patrocínio) e República (João Cardoso, Rui Barbosa, Capp, Bocaiuva, Vicente de Sousa e outros).

"Por atos como a encenação de $O$ escravo e por escritos, até de abolicionistas, erigiu-se uma simbologia da abolição que empurrou o movimento e mais ainda os escravos para o fundo da cena, enquanto a princesa se transfigurava em "Redentora" (p.369)8.

\section{Pontuações finais}

Um dos muitos méritos de Flores, Votos e Balas é o de recolar na agenda historiográfica brasileira o debate sobre as causas que levaram a abolição. Com uma análise ancorada numa visão ampla do movimento abolicionista em três fases, cada uma delas marcada por especificidades, convida os leitores a acompanhar de perto o complexo processo que culminou a Lei Áurea de 1888.

$\mathrm{Na}$ fase das flores (1868-1878), o movimento ganha o espaço público dos centros urbanos, modernizados pela atuação do gabinete de Rio Branco. Neste período, tomamos conhecimento da atuação de Abílio César Borges (1836-1891), que até então permanecera na sombra nos estudos sobre a abolição e da incansável atuação de André Rebouças. Na segunda fase dos votos (1879-1885), nela a

\footnotetext{
${ }^{8}$ Para informações sobre a Princesa Isabel, ver BARMAN, 2002.
} 
militância abolicionista atua na esfera político institucional, lutando para criar uma legislação que levasse a abolição. Na última fase das balas(1885-1888), com a perda das eleições e com a nomeação pelo Imperador de um gabinete escravista, abolicionistas e republicanos passaram a agir na clandestinidade. Nas palavras da autora: "o bloqueio escravista empurrava o movimento a descrer das instituições, o modelo de abolicionismo parlamentar inglês, e a cortejar a insurreição” (p.235).

A autora, na análise destas três fases, tem sempre presente as relações entre a campanha abolicionista e o sistema político. Relação importante, mas que não pode ser absolutizada, pois corre-se o risco de torná-la a única causa explicativa de um processo transpassado por outras variáveis. Relembra que o fato dos abolicionistas operaram em áreas distintas, não se excluíam mutuamente, pelo contrário havia um reconhecimento mútuo. Eles lançaram mãos de todos os instrumentos disponíveis e os utilizaram de acordo com a maior ou menor abertura sócio- política.

Alonso apresenta, no tópico intitulado o abolicionismo como movimento social (p.351-357), uma refinada síntese, um flashback da longa e complexa narrativa do processo abolicionista, autentico roteiro de leitura do texto.

Alguns pontos podem ser mais explorados, dado a o potencialidade dos mesmos para ampliar o horizonte analítico, como as relações entre a campanha abolicionista de libertação dos territórios e o tráfico interprovincial e o impacto na sociedade brasileira da guerra civil americana9.

Um ruído permanece ao longo da leitura, presente já no início da obra, quando a autora afirma que a abolição não "foi nem obras dos escravos, nem da princesa” (p.17). Nada contra resgatar a importância do movimento abolicionista, resgate por sinal necessário e realizado com competência, mas não explicitar a

${ }^{9}$ Consultar o texto de HORNE, 2010. 
importância da participação dos escravizados é negligenciar, mesmo não sendo esta a intenção da autora, o quanto a pesquisa historiográfica avançou.

A presença dos três abolicionistas negros na obra José do Patrocínio, André Rebouças e Luiz Gama lembra o leitor a contribuição negra. Contribuição esta, mais explicitada na última fase, quando ocorre uma aliança entre escravizados e abolicionistas, que patrocinam redes de fugas. No entanto, como em nenhum momento se explicitou ou acolheu a efetividade dos escravizados, a ação deles pode ser vista numa perspectiva mimética, imitam a opção pela clandestinidade, pela desobediência do movimento abolicionista ${ }^{10}$.

Angela Alonso com Flores, votos e balas ganhou o prêmio Jabuti-2015, como todo o mérito. Sua pesquisa realizada com paixão e competência vasculhou exaustivamente fontes primárias/jornais, atas e documentos oficiais e fontes manuscritas/ arquivos, documentos impressos, além de abrir o diálogo com uma bibliografia internacional e nacional. Ao longo do texto mantem um permanente e sugestivo diálogo com a literatura

Como afirmei no início, muitos são os méritos da obra, que dialoga tanto com especialistas na área, como com o público interessado em conhecer um pouco do nosso passado. Além de termos em mãos uma edição bem cuidada, trazendo anexos, cronologias e mapas que facilitam o acompanhamento da complexa dinâmica deste movimento social brasileiro com seus avanços, recuos e retomadas. A leitura, com frequência, remete-nos aos problemas atuais.

Nos últimos anos a temática da abolição tem sido objeto de estudo tanto na Europa como nos Estados Unidos e, principalmente, no Brasil depois de 1988. Indicamos ainda três textos que trazem informações complementares ao texto de Angela Alonso.

${ }^{10}$ Com relação a efetividade dos escravizados temos uma breve sinalização: "fugas dependiam da participação ativa dos escravos" (Cf. p.306). 
O primeiro é o magnifico estudo de Seymour Drescher, 2010 (Abolição. Uma história da escravidão e do antiescravismo. São Paulo: UNESP, 2010). O autor analisa num arco de longa duração "a interação intercontinental da violência, dos sistemas econômicos, e da sociedade civil com o fluxo e o refluxo da escravidão e do antiescravismo" (DRESCHER, 2010, p. XII). Aponto algumas ideias marcantes do texto: o fato da humanidade ter, durante um amplo arco de tempo, considerado a instituição da escravidão como natural, necessária e universal; o fato da expansão marítima ter corroborado com a expansão da escravidão, como forma de produção e controle social; o fato do resgate das petições depois de 1780 na Inglaterra, que acabou levando as classes trabalhadoras a darem suporte ao movimento antiescravista; e o fato do movimento antiescravista ter surgido quando a instituição escravista atingia o seu zênite na produção e acumulação de riquezas. O leitor tem em mãos um dos estudos mais amplos e detalhados sobre a escravidão e o antiescravismo, em especial nas Américas.

O segundo texto é de Célia Maria Marinho de Azevedo, 2003 (Abolicionismo. Estados Unidos e Brasil, história comparada (Século XIX). São Paulo: Annablume, 2003). A autora compara os abolicionismos americano e brasileiro explicitando as influências mútuas entre abolicionistas dos dois países e suas relações com abolicionistas europeus. Mostra a diferente recepção pelos abolicionistas de ambos os países de fatos marcantes como a Revolução do Haiti e a Guerra Civil Americana. Recepção que refletirá de maneira distinta no destino dos ex-escravizados e na questão racial.

O terceiro e último texto é de Luiz Gustavo Santos Cota, sua tese de doutorado, intitulada “Ave, Libertas: abolicionismos e luta pela liberdade em Minas Gerais na última década da escravidão”, defendida na Universidade Federal Fluminense em 2013. Ele busca compreender a atuação abolicionista em Minas Gerais durante a década de 1880. Examina as ações de militantes antiescravistas, escravos, senhores e autoridades públicas. Explicita a diversidade de posicionamento em relação à campanha pela abolição na Província de Minas Gerais, sendo que a atuação de grupos abolicionistas na região gerou muita tensão. 
Esses textos olham o processo abolicionista sob diversos ângulos: Drescher, globalmente; Azevedo de forma mais circunscrita nas Américas; e Cota, em Minas Gerais.

Finalizando, Janio de Freitas, comentando o massacre no Complexo Penitenciário Anísio Jobim, em Manaus, confirma a triste atualidade da mentalidade das instituições escravistas, que se perpetuaram na sociedade brasileira. "Aquelas mesmas que, originadas na escravidão aqui mantida até o último limite, transpuseram-se para as relações econômicas, sociais e culturais da classe escravagista e seus novos subjugados - os ex-escravos abandonados no tempo e no espaço, acrescidas da miséria cabocla. Qualquer cidade é um atestado vivo de que o Brasil não teve mudança essencial com o fim formal da escravidão" (FREITAS, 2017, p.6).

\section{REFERÊNCIAS}

ALONSO, Angela. Flores, votos e balas. O Movimento Abolicionista brasileiro (18681888). São Paulo: Companhia das Letras. 2015. ISSN. 978-85-359-2661-3

AZEVEDO, Célia Maria Marinho de. Abolicionismo. Estados Unidos e Brasil, história comparada (Século XIX). São Paulo: Annablume, 2003.

AZEVEDO, Elciene. O direito dos escravos. Lutas jurídicas e abolicionismo na província de São Paulo. Campinas: Ed. Da Unicamp, 2010.

AZEVEDO, Elciene. Orfeu de carapinha. A trajetória de Luís Gama na imperial cidade de São Paulo. Campina: Ed. Da Unicamp, 1999.

BARMAN, Roderick. A princesa Isabel. Gênero e poder no século XIX. São Paulo: UNESP, 2002.

COTA, Luiz Gustavo Santos. Ave, Libertas: abolicionismos e luta pela liberdade em Minas Gerais na última década da escravidão. 2013. 318f. Tese (Doutorado) - Universidade Federal Fluminense, Rio de Janeiro.

DRESCHER, Seymour. Abolição. Uma história da escravidão e do antiescravismo. São Paulo: UNESP, 2010.

FREITAS, Jânio de. O crime da Indiferença. Folha de São Paulo, São Paulo, p. 6, 5 de janeiro de 2017. 
HORNE, Gerard. O Sul mais distante. O Brasil, os Estados Unidos e o tráfico de escravos africanos. São Paulo: Companhia das Letras, 2010.

MACHADO, Maria Helena P. T; CASTILHO, Celso T. Torando-se livre. Agentes históricos e lutas sociais no processo de Abolição. São Paulo: EDUSP, 2015.

MENDONÇA, Joseli Maria Nunes. Entre a mão e os anéis. A lei dos Sexagenários e os caminhos da Abolição no Brasil. Campinas: Ed. Unicamp/Cecult, 1999.

PARRON, Tâmis. A política da escravidão no Império do Brasil, 1826 -1865. Rio de Janeiro: Civilização Brasileira, 2011.

SCHAMA, Simon. Travessias difíceis. Grã-Bretanha, os escravos e a Revolução Americana. São Paulo: Companhia das Letras, 2001. 